\title{
A REVIEW ON TRANSDERMAL PATCHES USED AS AN ANTI-INFLAMMATORY AGENT
}

\author{
DEIJY CHOUDHURY, KOUSHIK NANDAN DUTTA, RAMEN KALITA*
}

Department of Pharmacology, NETES Institute of Pharmaceutical Science, Santipur, Assam, India. Email: ramengips89@gmail.com

Received: 01 October 2021, Revised and Accepted: 15 November 2021

\begin{abstract}
The transdermal drug delivery system is widely accepted due to its numerous advantages as it is a non-invasive drug administration process with prolonged therapeutic effect, reduced side effects, improved bioavailability, better patient compliance, and easy termination of drug therapy. Nonsteroidal anti-inflammatory drugs such as Diclofenac sodium, Lornoxicam, Aceclofenac, Ibuprofen, antihypertensive drugs, for example, Repaglinide, Atenolol, and Antiviral agents such as Stavudine, zidovudine represents the most commonly used medications for the treatment of pain and inflammatory reaction but various side effects can limit their use. Therefore, transdermal delivery of these drugs has advantages of avoiding hepatic first-pass effect, gastric irritation and delivering the drug for an extended period of time at a sustained level. The present article mainly focuses on the work been done on these drugs by formulated and delivered as transdermal patches to decrease the side effects related to the oral delivery.
\end{abstract}

Keywords: Transdermal patch, Non-steroidal anti-inflammatory drugs, Repaglinide, Diclofenac sodium, Inflammation.

(C) 2021 The Authors. Published by Innovare Academic Sciences Pvt Ltd. This is an open access article under the CC BY license (http://creativecommons.org/ licenses/by/4.0/) DOI: http://dx.doi.org/10.22159/ajpcr.2021v14i12.43277. Journal homepage: https://innovareacademics.in/journals/index.php/ajpcr

\section{INTRODUCTION}

\section{Inflammation}

Inflammation is a process that occurs after an infection or tissue injury. The inflammatory response is essential in maintaining homeostasis which leads to tissue damage due to fibroplasia, leukocytosis, excessive production of cytokines and other mediators such as tumor necrosis factor- $\alpha$-alpha, interleukin (IL)-6, and IL-8. Inflammation is also an important physical factor that triggers the immune reaction [1]. Superficial pain arises from nociceptive receptors in the skin and mucous membranes and is often associated with inflammation and tissue swelling [2]. In general, non-steroidal anti-inflammatory drugs (NSAIDs) can be used for the treatment of pain and inflammation. The NSAIDs can inhibit the activity of cyclooxygenase enzymes (COX-1 and COX-2) and therefore inhibit the synthesis of thromboxanes and prostaglandins $\left(\mathrm{PGE}_{2}\right)$ [3]. COX enzyme is released during pain and inflammation, whereas thromboxanes and $\mathrm{PGE}_{2}$ are considered as the mediators of allergic reactions such as vasoconstriction and inflammation. [4]. Example of some commonly used NSAIDs includes aspirin, ibuprofen, naproxen and diclofenac. Diclofenac is used for the treatment of mild to moderate muscular pain and to alleviate the symptoms of arthritis, menstrual cramps, toothache and migraines/headaches [5]. However, if it is taken orally for a long period of time in high doses then it may lead to fatal stomach, intestinal bleeding and heart attack or stroke [6].

As an alternative to oral drug delivery and parenteral administration for NSAIDs, now a days Transdermal drug delivery (TDD) is mostly preferred reasons [7]. Among the various advantages, one advantage is that the transdermal route avoids the metabolism of the drug inside the liver and its rapid absorption inside the gastrointestinal (GI) tract, thus avoiding the risk of internal bleeding and irritation. In the TDD systems, drugs are specifically designed to deliver a predestined amount of drug through the stratum corneum and the systemic circulation [8]. The choice of drug for TDD depends on the size of the drug, as it can pass through the skin pores. However, improper use of the strong ointments can potentially lead to skin allergies, dryness, lesions, and thinning of the skin [9].

In TDDS systems mostly drug-loaded patches, backing films, microneedles, thermal, mechanical and electrical ablation, are often preferred [10]. For treatment of muscular pain, a few transdermal patches are available on the market and these are mostly based on either narcotic (Fentanyl) or methyl salicylate (Salonpas), which can cause breathing problems, or toxicity issues [11,12]. TDD system allows the administration of potent drugs with the benefit of self-administration and enhanced therapeutic efficacy [13]

It is caused by injury to the living tissue. It involves the 4 primary indicators of inflammation that is pain, redness, heat, swelling. The role of inflammation such as healing, restorative process and also having an aggressive role, which is more widely recognized [14]

Inflammation is a programmed local tissue response $\downarrow$

Peculiar to vascularized living tissue

The inflammatory response involves different events which can be elicited by numerous stimuli, for example, chemical, thermal injury and antigen-antibody interactions. The different events of inflammation are underlined different manifestations that is induced and regulated by a large number of chemical mediators, eicosanoids, kinins, etc. [14]. The main aim of inflammatory response is to localize and eliminates the harmful agents; secondly remove the damaged tissue components to culminate in the healing of the affected tissues [15].

\section{THE INFLAMMATORY RESPONSE}

$\mathrm{PGE}_{2}$ has various physiological roles including regulation of normal body temperature, renal blood flow, gastric mucosal integrity, etc. The pathway of PGs synthesis starts with the generation of arachidonic acid from cell membrane phospholipid by PLA2. Then, arachidonic acid is converted to PGs by the enzyme COX. Mostly the inducible enzyme COX-2 is acting as the most active during inflammatory processes. LTs are produced by the enzyme 5-lipooxygenase. It is highly associated with an inflammatory condition that is nitric oxide synthase which produces NO and causes inflammation. According to the WHO, in 2018 approx 235 million people suffer from inflammation in the world. The symptomatic relief provides relief to the patient suffering from inflammatory autoimmune diseases (Fig. 1).

Inflammation is classified into two types

- Acute inflammation

- Chronic inflammation. 


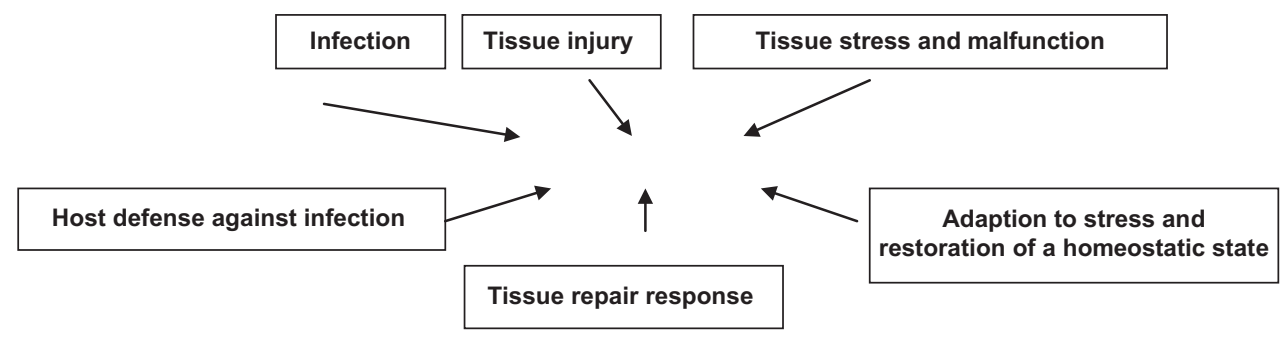

Fig. 1: Inflammatory responses

Acute inflammation is defined as a rapid response to a harmful agent that serves to deliver mediators of host defense, leukocytes, and plasma proteins to the site of injury. It gives an initial response of the body to harmful stimuli [16].

\section{ACUTE INFLAMMATION HAS 3 MAJOR COMPONENTS}

- Alterations in the vascular caliber that lead to an increase in blood flow

- Structural changes in the microvasculature that permits plasma proteins and leukocytes to leave the circulation

- Leucocyte emigrates from the microcirculation, their accumulation within the focus of injury and their activation to eliminate the offending agent.

\section{CHEMICAL MEDIATORS OF ACUTE INFLAMMATION}

- Histamine: increased permeability

- $\mathrm{PGE}_{2}$ : vasodilation

- Leukotrienes: increased permeability.

\section{Morphology of acute inflammation}

- Pseudomembranous inflammation

It is an inflammatory response of the mucous surface to toxins of diphtheria or irritant gases.

- Ulcer

Ulcers are local defects on the surface of an organ produced by inflammation.

- Cellulitis

Due to the spreading effects of substances such as hyaluronidase released by some bacteria, diffuse inflammation of soft tissues can take place [17].

Chronic inflammation can be defined as a prolonged process in which tissue destruction and inflammation occur at the same time. In general, for chronic inflammation, the extent and effects of inflammation may vary with the cause of the injury and the ability of the body to repair and overcome the damage. In this inflammation process, the inflammatory response is out of a fraction resulting in damage to the body [18]. Common symptoms of chronic inflammation are fatigue, fever, mouth sores, rashes, abdominal pain, etc. In chronic inflammation, disorders, such as arthritis and hemorrhoids, that continued to torment humanity despite nature's endowment of medicinal plant resources (Fig. 2) [19].

\section{GENERAL FEATURES OF CHRONIC INFLAMMATION}

- Mononuclear cell infiltration: phagocytes, circulating monocytes, macrophages, etc.

- Tissue destruction or necrosis

- Proliferative changes: small blood vessels and fibroblasts.

Nonsteroidal anti-inflammatory drugs are the agents which suppresses the inflammation. These agents have also adverse effects such as peptic ulceration and osteoporosis [20]. NSAID'S are one of the common therapeutic agents used for the treatment of pain, fever, and inflammation. Examples: Diclofenac, Ibuprofen, Naproxen, and Celecoxib [21].

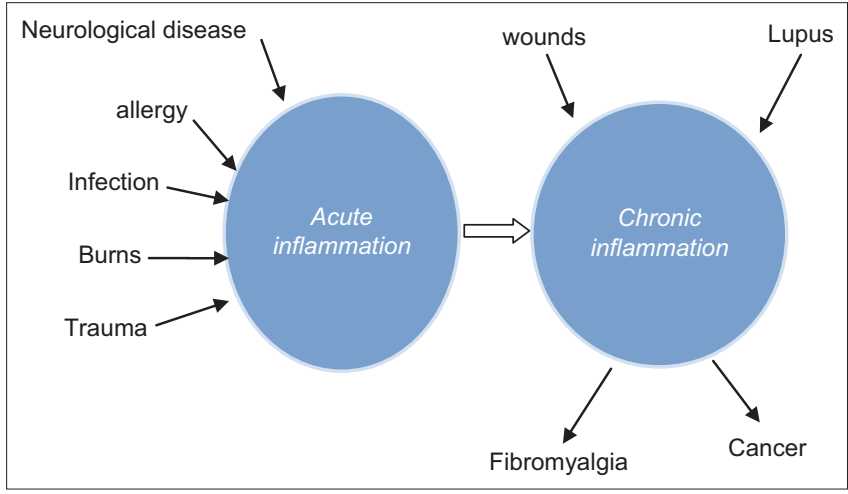

Fig. 2: Causes of acute and chronic inflammation

In this review, we are discussing the different types of the transdermal patchs.

\section{TRANSDERMAL PATCH}

The Transdermal patch is medicated adhesive patch. These are prepared which deliver a therapeutically effective amount of drugs across the skin. The patches provide a controlled release of the medication into the patient (Fig. 3).

It acts as a carrier for a drug which holding it until the point of application. At this point, the adhesive secures the patch to the skin. It allows the drug access to the skin, it helps the permeation process. It delivers the drugs topically. A transdermal patch containing a high dose of drug into the skin which is retained for a prolonged period of time, gets entered the blood flow through the diffusion process.

\section{Advantages}

1. Self- medication is possible

2. Unwanted side effects get minimized

3. First pass metabolisms of drug get avoided.

\section{Disadvantages}

1. Larger molecules size of the drug creates difficulty in absorption

2. Chances of allergic reactions at the site of applications such as itching, rashes, etc.

Transdermal drug administration generally refers to the topical application which intact in the skin simultaneously minimizes the retention and also metabolism of the drug in the skin. TDD systems are used in the skin disorders, pains, angina pectoris, neurological disorders, etc. TDD systems are considered as the new drug delivery systems which involve the demonstration of clinical safety and effectiveness of the drug. In novel techniques, drug delivery has been investigated in human medicine in recent years. Among the new drug delivery systems, there are mostly used for transdermal applications [21].

\section{Limitations of TDD systems}

- It cannot administer drugs that require high blood levels

- Drug formulation may cause irritation or sensitization. 


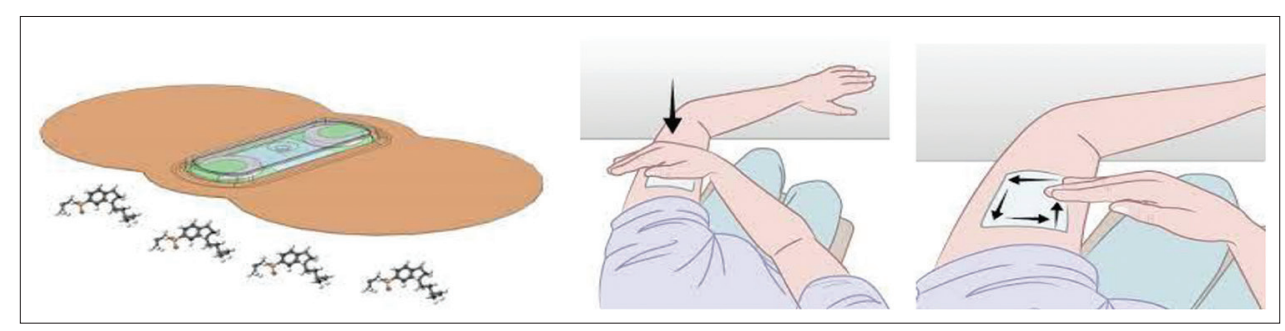

Fig. 3: Types of patchs

\section{Components of transdermal patches}

The basic components of transdermal patches are consist of a polymer matrix, drug reservoir, active ingredient, permeation enhancers, backing laminates, adhesives, plasticizers, solvents, etc. [22].

\author{
Transdermal patches are categorized into 3 categories \\ - First -generation \\ - Second generation \\ - Third generation.
}

In the $1^{\text {st }}$ generation transdermal patches, it is used in clinics. These are consisting of the drug in a reservoir that is enclosed by one side with impermeable adhesives. In the $2^{\text {nd }}$ generation, the transdermal patches increased the skin permeability which reduces damage to deeper tissues. Again In the $3^{\text {rd }}$ generation, the transdermal patches increased the skin penetration of drugs which also protect the deeper tissues [22]. Transdermal patches are generally provided constant blood levels but avoid the first-pass metabolism. It increased patient compliance.

\section{Method of preparation of transdermal patches \\ - Asymmetric TPX membrane method \\ - Circular teflon mould method \\ - EVAC membrane method \\ - Mercury substrate method.}

Selection of drug candidate for the transdermal delivery system The drug candidate should be:

- Adequate skin permeability

- Adequate skin acceptability

- Adequate clinical need.

\section{Examples of transdermal patches}

Transdermal patch of diclofenac sodium

It has been investigated that diclofenac sodium patches using chitosan and polyvinyl alcohol (PVA) cross-linked tripolyphosphate sodium to increased transdermal permeation of the drug from the matrix system across rabbit skin

The investigation of diclofenac sodium patch was done by ultraviolet spectrophotometry. Determination of physical characteristics of the film includes the weight test, thickness, organoleptic observation, interaction between materials used in Fourier transform infrared (FTIR). It has been observed that the result of physicochemical parameters of the transdermal patches has been found satisfactory. The FTIR data of rabbit skin indicated chitosan and PVA alcohol crosslinked TPP increases transdermal permeation of Diclofenac sodium in the stratum corneum [23]. An ideal transdermal patch should have flexibility, elasticity, and softness and at the same time must have sufficient strength to follow the body contours. It also has good adhesive strength for prolonged retention on the skin for the desired duration of action. In addition, various permeation enhancers and chemicals are used to improve penetration across the skin, including alcohols, terpenes, and surfactants $[24,25]$.

Postsurgical pain has often been a nemesis for surgeons and patients alike due to a considerable degree of inflammatory response involved. NSAIDs are among the most generally utilized medication as because they decrease the inflammatory responses [26]. Diclofenac sodium, an aryl acetic acid derivative is the regularly utilized NSAID either as a sole agent or in combination with different NSAIDs [5]. It is a nonselective cox inhibitor (conventional NSAID) that acts by inhibiting COX enzyme [27]. A benefit of a transdermal medication over different kinds such as oral, skin, and so on, is that it gives a controlled release of the medicament into the circulation [11]. The transdermal diclofenac patch (Nu Patch) is utilized to relieve postoperative pain. It is applied once for the span of $24 \mathrm{~h}$ and produces quick relief from discomfort with negligible or no side effects. The patch is to be applied on the skin, ideally in a space without any hair [28]. The patch achieves plasma levels ranging between 20 and $50 \mathrm{ng} / \mathrm{ml}$ and it is lesser when compared to the oral route [29].

\section{Transdermal gel patch of lornoxicam (LRX)}

LRX is a potent NSAID that belongs to oxicam class. It is mainly used in chronic pain and inflammatory conditions. It also shows numerous GI, renal, and hematological adverse effects when taken orally [30]. Frequent administration of LRX is required due to its short halflife (3-4 h). However, in the case of chronic conditions parenteral administration is not recommended [31]. Oleic acid (OA) has been widely used for improving percutaneous drug absorption. It has been proved that the use of $\mathrm{OA}$ with propylene glycol gives satisfactory results in many transdermal formulations [24,32,33]. LRX, similar to other NSAIDs, decreases the $\mathrm{PGE}_{2}$ synthesis by inhibiting both isoforms of the COX enzymes in the same proportions [34]. Inhibition of (PG) synthesis help to protect the gastrointestinal mucosal membrane by preventing the gastric acid secretion and it also strengthened the mucosal barrier for gastric acid. However, the inhibition of PG synthesis may cause heartburn, mild dyspepsia, ulceration, and hemorrhage [35].

Sodium alginate is a biopolymer that has been widely used as a binding and disintegrating agent in the formulation of tablets [36,37]. Sodium alginate has a unique ability to form gel in the presence of calcium chloride, and it also delays the dissolution of a drug from sustained -release formulations [38]. The permeation enhancers are used to facilitate the transdermal delivery of hydrophilic and lipophilic medications, for example, dimethyl sulfoxide [39]. The membranebased transdermal patches for LRX gel have been studied using OA and polypropylene glycol as penetration enhancers to improve the drug delivery across the skin and also evaluated the In vivo analgesic and anti-inflammatory activity. It has been previously demonstrated that the fabricated transdermal gel patch of LRX can deliver the drug through the skin in a controlled release manner with desired antiinflammatory activity [40].

\section{Transdermal patch of repaglinide}

The transdermal patch of repaglinide has been prepared to sustain the release and improve the bioavailability of drug and patient compliance. The formulations were prepared by solvent casting method. The prepared formulations were evaluated for various parameters such as tensile strength, \%drug content, \%moisture content, and folding endurance. Repaglinide has the half- life of $1 \mathrm{~h}$, bioavailability in the body is $56 \%$ due to first-pass metabolism [41]. Diabetes mellitus is a chronic metabolic disorder mainly caused by hyperglycemia caused by insulin deficiency, and it is often combined with insulin 
resistance [42]. Repaglinide belongs to meglitinide class of drugs used to treat noninsulin-dependent diabetes mellitus. Repaglinide is generally given in a dose of $0.5-4 \mathrm{mg}$ (3-4 times) in a day. The melting point of Repaglinide is $130-131^{\circ} \mathrm{C}$ and has mol. wt. of 452.58 [43,44]. It has been proved that repaglinide produces hypoglycemia after oral administration [45]. The Topical preparation of repaglinide may be beneficial to the patient since it reduces adverse effects and avoids the hepatic first-pass metabolism $[46,47]$.

\section{Transdermal patch of atenolol}

Atenolol is a beta-adrenergic receptor blocking agent used for the treatment of hypertension [48,49]. The elimination half -life is 6-7 $\mathrm{h}$ after oral administration. The absolute bioavailability is approximately $50 \%$ due to first -pass metabolism $[50,51]$. The action of the sympathetic nervous system is blocked by Atenolol. On the basis of that, a transdermal patch has been prepared by using cellulose acetate phthalate, polyvinyl pyrrolidine, and polyethylene glycol [52]. The purpose of the study was to provide the delivery of the drug at a controlled rate across intact skin [53]. It has been reported that administration of conventional tablets of atenolol exhibits fluctuations in the plasma drug level which results in either manifestation of side effects or reduction in drug concentration at the receptor site $[54,55]$. The researchers developed a transdermal delivery system containing atenolol and hydrochlorothiazide might be a milestone in the combinational therapy of hypertension [56]. The in vivo evaluation of formulation (2\% Eudragit RS 100, 1\%HPMC) has been studied and it shows a better correlation with the in-vitro drug release which confirms the achievement of targets of the present study such as controlled prolonged zero-order release, reduced frequency of administration, greater therapeutic effect, overcome the side effects, simplify the treatment regimen and thus may improve patient compliance [57]. A study of transdermal patch of Atenolol has been carried out to develop matrix-based transdermal patches which containing Atenolol. The patches were prepared by solvent casting method.

\section{Transdermal patch of Stavudine}

The matrix-type TDD systems of Stavudine have been developed using hydrophilic and hydrophobic polymers for controlled release, showed suitable physicochemical properties. It has been confirmed that Stavudine permeated through the rat abdominal skin and hence could permeate through the human skin $[19,58]$. Another study revealed that the Transdermal patch of Stavudine has been prepared by using different concentrations of Eudragit RS 100 and Eudragit RL 100. These Prepared patches were found to have smooth and uniform surfaces when they are functional onto the skin $[59,60]$. It has been proved that the transdermal patch of Stavudine improves the bioavailability of drugs and patient compliance. These patches were characterized by Field Emission Scanning Electron Microscopy. Stavudine has the half -life of $1-1.5 \mathrm{~h}$ and bioavailability in the body is $86 \%$ due to firstpass metabolism [18].

\section{Transdermal patch of Aceclofenac}

ACF inhibited the enzyme COX enzyme. In vitro data revealed that the inhibition of Cox-1 and Cox- 2 by ACF in whole blood assays, with selectivity for Cox-2 being evident [61]. If ACF is used in patients with ankylosing spondylitis, it reduces the duration of morning stiffness and pain intensity and also improved the spinal mobility [62]. ACF is metabolized to a major metabolite, 4'-hydroxy ACF, and various metabolites including 5-hydroxy ACF, 4'- hydroxydiclofenac, diclofenac, and 5-hydroxydiclofenac [63]. It has been previously described the use of hydroxyl propyl cellulose in transdermal patches and ophthalmic preparations and ethyl cellulose transdermal delivery systems as well as other dosage forms for controlled release of drugs [64-67]. Aceclofenac transdermal patch has been prepared by using a combination of HPMC and MC. A study was conducted using HPMC and MC (50:50) with $30 \%$ plasticizer and the results showed that it may be suitable for the development of TDD systems of Aceclofenac [68,69].
Transdermal patch of Zidovudine

Zidovudine (AZT) is a polar molecule. The diffusion of AZT across stratum corneum is poor and below the level to achieve effective therapeutic plasma concentration [70]. It has been previously studied that using terpenes (anethole) along with polyols such as propylene glycol and polyethylene glycol as penetration enhancers could be effective in achieving therapeutic plasma levels for AZT [42,71]. Immediately after intravenous or oral administration, AZT showed excessive plasma level [72]. Therefore, the delivery from a non-oral pathway such as the transdermal route may be helpful in maintaining suitable plasma concentration and also useful in improving bioavailability and patient compliance and in avoiding side effects $[73,74]$. The benefit of transdermal delivery of AZT has been successfully studied $[75,76]$.

\section{Transdermal patch of ibuprofen}

Ibuprofen is employed to ease moderate pain, reduce swelling, control fever, and treat arthritis at higher doses [77,78]. However, along with other NSAIDs, ibuprofen causes (gastritis) which may result in a stomach ulcer or even bleeding $[79,80]$. A novel TEPI ${ }^{\circledR}$ transdermal patch technology is reported and is exemplified with ibuprofen as the active pharmaceutical ingredient and a new HMPSA cross-linked polymer excipient as a drug reservoir [81,82]. The transdermal patchs of ibuprofen has been evaluated through its organoleptic, weight uniformity, drug content, etc. Ibuprofen is an NSAID drug. It causes gastric irritation when administered orally. The evaluation and formulation of transdermal patch of Ibuprofen have been carried out to prevent this side effect [16]

\section{DISCUSSION}

In this review article, we provided valuable information regarding the TDD systems, transdermal patches, and their physicochemical parameters. Furthermore discussed the inflammation, mechanisms of inflammation, studied about the anti-inflammatory drugs, types of inflammation, etc.

\section{CONCLUSION}

TDD systems have been effective for painless, efficient, non-toxic, and patient-compliant drug delivery. The development of an efficient means of transdermal administration of NSAIDs may increase local soft tissue and joint concentrations and also reduces the side effects associated with oral administration. Various NSAID drugs may be incorporated for targeting a variety of skin disorders but all NSAIDs cannot be given by this route because of their physicochemical properties which are essential for the transdermal delivery of drugs. Therefore, the potential of this delivery system needs to be explored in the case of NSAIDs. The Transdermal patch of Repaglinide improves the bioavailability of drug and patient compliance. Stavudine has the ability to permeate through the rat abdominal skin and hence could permeate through the human skin. Terpenes (anethole) along with propylene glycol and polyethylene glycol as penetration enhancers could be effective in achieving therapeutic plasma levels for AZT. The Transdermal patch of Atenolol provides the delivery of the drug at a controlled rate across intact skin. Moreover, the transdermal patch has enormous potential to be used not only for the management of inflammatory reactions but also for other conditions requiring transdermal drug release. Moreover, the transdermal patch has enormous potential to be used not only for the management of inflammatory reactions but also for other conditions requiring transdermal drug release.

\section{ACKNOWLEDGMENT}

The authors would like to acknowledge NETES Institute of Pharmaceutical Science, Mirza, Santipur, Assam, for providing their lab facilities and library.

\section{AUTHORS' CONTRIBUTIONS}

Manuscript framing and the concept has been presented by Deijy Choudhury. Literature search and preparation have been done by Mr. 
Ramen Kalita. Reviewing and editing have been done by Mr. Koushik Nandan Dutta.

\section{CONFLICT OF INTEREST STATEMENT}

The authors have declared no conflicts of interest.

\section{AUTHORS FUNDING}

NIL

\section{REFERENCES}

1. Chen L, Deng H, Cui H, Fang J, Zuo Z. Inflammatory responses and inflammation-associated diseases in organs. Oncotarget 2018;9:7204-18

2. Sogaard K, Sjogaard G. Physical activity as cause and cure of muscular pain: Evidence of underlying mechanisms. Exerc Sport Sci Rev 2017;45:136-45

3. Pascottini OB, Spricigo JF, Van Schyndel SJ, Mion B, Rousseau J, Weese JS, et al. Effects of parity, blood progesterone, and non-steroidal anti-inflammatory treatment on the dynamics of the uterine microbiota of healthy postpartum dairy cows. PLoS One 2021:16:e0233943.

4. Sharma CS, Khandelwal M. A novel transdermal drug-delivery patch for treating local muscular pain. Ther Deliv 2018;9:405-7.

5. Diwan V, Srinivasa TS, Ramreddy KY, Agrawal V, Nagdeve S, Parvez H. A comparative evaluation of transdermal diclofenac patch with oral diclofenac sodium as an analgesic drug following periodontal flap surgery: A randomized controlled clinical study. Indian J Dent Res 2019;30:57-60.

6. Gunter BR, Butler KA, Wallace RL, Smith SM, Harirforoosh S. Nonsteroidal anti-inflammatory drug-induced cardiovascular adverse events: A meta-analysis. J Clin Pharm Ther 2017;42:27-38.

7. Zhang D, Bian Q, Zhou Y, Huang Q, Gao J. The application of label-free imaging technologies in transdermal research for deeper mechanism revealing. Asian J Pharm Sci 2021;16:265-79.

8. Hua S. Advances in nanoparticulate drug delivery approaches for sublingual and buccal administration. Front Pharmacol 2019;10:1-9.

9. Xie Y, Shao R, Lin Y, Wang C, Tan Y, Xie W, et al. Improved therapeutic efficiency against obesity through transdermal drug delivery using microneedle arrays. Pharmaceutics 2021;13:827.

10. He X, Sun J, Zhuang J, Xu H, Liu Y. Microneedle system for transdermal drug and vaccine delivery: Devices, safety, and prospects. Dose Response 2019;17:1559325819878585.

11. Pandey PC, Shukla S, Skoog SA, Boehm RD, Narayan RJ. Current advancements in transdermal biosensing and targeted drug deliver. Sensors (Basel) 2019;19:1028.

12. Grammatikopoulou MG, Gkiouras K, Dardiotis E, Zafiriou E, Tsigalou C, Bogdanos DP. Peeking into the future: Transdermal patches for the delivery of micronutrient supplements. Metabol Open 2021;11:100109.

13. Szunerits S, Boukherroub R. Heat: A highly efficient skin enhancer for transdermal drug delivery. Front Bioeng Biotechnol 2018;6:15.

14. Sarveswaran R, Jayasuriya WJ, Suresh TS. In vitro assays to investigate the anti-inflammatory activity of herbal extracts: A review. World J Pharm Res 2017;6:131-41.

15. Elkoshi Z. The binary classification of chronic diseases. J Inflamm Res 2019;12:319-33

16. Nilewar GA, Takdhat PL, Thakre SM, Bhagwatkar PD. Formulation and evaluation of repaglinide transdermal patches for treatment of diabetes. World J Pharm Res 2018;7:1342-53.

17. Kriplani P, Sharma A, Aman, Pun P, Chopra B, Dhingra A, et al. Formulation and Evaluation of Transdermal Patch of Diclofenac Sodium. Glob J Pharm Pharm Sci 2018;4:1-4

18. Saroj AK, Khan R, Sharma B. Transdermal drug delivery system (Patch). World J Pharm Res 2019;8:325-43

19. Cherukuri S, Batchu UR, Mandava K, Cherukuri V, Ganapuram KR. Formulation and evaluation of transdermal drug delivery of topiramate. Int J Pharm Investig 2017;7:10-7.

20. Mahesh G, Kumar KA, Reddanna P. Overview on the discovery and development of anti-inflammatory drugs: Should the focus be on synthesis or degradation of PGE? J Inflamm Res 2021;14:253-63.

21. KarNR. A review on inflammatory bowel disease- recent pharmaceutical approaches to combat it. Int J Pharm Sci Res 2021;12:3593.

22. Saleem S, Muhammad G, Hussain MA, Abbas Bukhari SN. A comprehensive review of phytochemical profile, bioactives for pharmaceuticals, and pharmacological attributes of Azadirachta indica.
Phytother Res 2018;32:1241-72.

23. Lalitha P, Sachithanandam V, Swarnakumar NS, Sridhar R. Review on anti-inflammatory properties of Mangrove plants. Asian J Pharm Res 2019;9:273-88.

24. Dasari S, Yedjou CG, Brodell RT, Cruse AR, Tchounwou PB. Therapeutic strategies and potential implications of silver nanoparticles in the management of skin cancer. Nanotechnol Rev 2020;9:1500-21.

25. Amjadi M, Mostaghaci B, Sitti M. Recent advances in skin penetration enhancers for transdermal gene and drug delivery. Curr Gene Ther 2017;17:139-46.

26. McEvoy L, Carr DF, Pirmohamed M. Pharmacogenomics of NSAID-induced upper gastrointestinal toxicity. Front Pharmacol $2021 ; 12: 684162$

27. Veettil SK, Lim KG, Ching SM, Saokaew S, Phisalprapa P, Chaiyakunapruk N. Effects of aspirin and non-aspirin nonsteroidal antiinflammatory drugs on the incidence of recurrent colorectal adenomas: A systematic review with meta-analysis and trial sequential analysis of randomized clinical trials. BMC Cancer 2017;17:763.

28. Rajeswari SR, Gowda T, Kumar T, Mehta DS, Arya K. Analgesic efficacy and safety of transdermal and oral diclofenac in postoperative pain management following dental implant placement. Gen Dent 2017;65:69-74.

29. Shinde VA, Kalikar M, Jagtap S, Dakhale GN, Bankar M, Bajait CS, et al. Efficacy and safety of oral diclofenac sustained release versus transdermal diclofenac patch in chronic musculoskeletal pain: A randomized, open label trial. J Pharmacol Pharmacother 2017;8:166-71.

30. Dasgupta S, Ray S, Dey S, Pal P, Mazumder B. Transdermal lipid nanocarriers: A potential delivery system for lornoxicam. Pharm Nanotechnol 2017;5:32-43

31. Palei NN, Mohanta BC, Das MK, Sabapathi ML. Lornoxicam loaded nanostructured lipid carriers for top-ical delivery: Optimization, skin uptake and in vivo studies. J Drug Deliv Sci Technol 2017;39:490-500.

32. Yu YQ, Yang X, Wu XF, Fan YB. Enhancing permeation of drug molecules across the skin via delivery in nanocarriers: Novel strategies for effective transdermal applications. Front Bioeng Biotechnol 2021;9:646554.

33. Ameen D, Michniak-Kohn B. Development and in vitro evaluation of pressure sensitive adhesive patch for the transdermal delivery of galantamine: Effect of penetration enhancers and crystallization inhibition. Eur J Pharm Biopharm 2019;139:262-71.

34. Shivakumar HN, Kotian RS. Design and development of transdermal drug delivery of nonsteroidal anti-inflammatory drugs: Lornoxicam 2019;8:277-83.

35. Yadav AV, Urade MN. Formulation and evaluation of chitosan based transdermal patches of lornoxicam for prolonged drug release and to study the effect of permeation enhancer. Indian J Pharm Educ Res 2019;53:88-96.

36. Manickam B, Sreedharan R, Chidambaram K. Drug/vehicle impacts and formulation centered stratagems for enhanced transdermal drug permeation, controlled release and safety: Unparalleled past and recent innovations-an overview. Curr Drug Ther 2019;14:192-209.

37. Puscaselu RG, Lobiuc A, Dimian M, Covasa M. Alginate: From food industry to biomedical applications and management of metabolic disorders. Polymers 2020;12:2417.

38. Opatha SA, Titapiwatanakun V, Chutoprapat R. Transfersomes: A promising nanoencapsulation technique for transdermal drug delivery. Pharmaceutics 2020;12:855.

39. Pereira R, Silva SG, Pinheiro M, Reis S, Vale ML. Current status of amino acid-based permeation enhancers in transdermal drug delivery. Membranes (Basel) 2021;11:343.

40. Ginting E, Reveny J, Sumaiyah. Formulation and evaluation of in vitro transdermal patch diclofenac sodium using chitosan polymer and polyvinyl alcohol cross linked tripolyphosphate sodium. Asian J Pharm Clin Res 2018;11:171-5.

41. Duriya H, Shoaib MH, Ali FR, Siddiqui F. Lornoxicam controlled release transdermal gel patch: Design, characterization and optimization using co-solvents as penetration enhancer. PLoS One 2020;15:1-23.

42. Ormazabal V, Nair S, Elfeky O, Aguayo C, Salomon C, Zuñiga FA. Association between insulin resistance and the development of cardiovascular disease. Cardiovasc Diabetol 2018;17:122.

43. Wang SL, Dong WB, Dong XL. Comparison of twelve single-drug regimens for the treatment of Type 2 diabetes mellitus. Oncotarget 2017:8:72700-13.

44. Lee YC, Chang CH, Dong YH. Comparing the risks of hospitalized heart failure associated with glinide, sulfonylurea, and acarbose use in Type 2 diabetes: A nationwide study. Int J Cardiol 2017;228:1007-14 
45. Delvecchio M, Pastore C, Giordano P. Treatment options for MODY patients: A systematic review of literature. Diabetes Ther 2020;11:1667-85.

46. Mhatre O, Sodha S. Pharmaceutical feasibility and flow characteristics of polymeric non-spherical particles. Nanomedicine 2019;18:243-58.

47. Reddy PS, Bose PS, Sruthi V, Saritha D. Investigation of Kondagogu gum to develop transdermal film of repaglinide. Asian J Pharm Clin Res 2018;11:440-5.

48. Tian F, Liu T, Xu G, Li D, Ghazi T, Shick T, et al. Adrenergic blockade bi-directionally and asymmetrically alters functional brain-heart communication and prolongs electrical activities of the brain and heart during asphyxic cardiac arrest. Front Physiol 2018;9:99.

49. Trivedi V, Arora N, Arora P. Formulation and evaluation of transdermal patches of atenolol. Int J Res Cult Soc 2018;2:13-8.

50. Grass J, Rose P, Burhenne J, Blank A, Haefeli WE, Mikus G. Absolute bioavailability of microdosed midazolam after buccal administration is dependent on buccal exposure time. J Clin Pharmacol 2021;61:472-9.

51. Delshadi R, Bahrami A, McClements DJ, Moore MD, Williams L. Development of nanoparticle-delivery systems for antiviral agents: A review. J Control Release 2021;331:30-44.

52. Ramkanth C, Chetty CM, Sudhakar Y, Thiruvengadarajan VS, Anitha P, Gopinath C. Development, characterization and in vivo evaluation of proniosomal based transdermal delivery system of atenolol. Future $\mathrm{J}$ Pharm Sci 2018;4:80-7.

53. Alkilani AZ, McCrudden MT, Donnelly RF. Transdermal drug delivery: Innovative pharmaceutical developments based on disruption of the barrier properties of the stratum corneum. Pharmaceutics 2015;7:438-70.

54. Irvine J, Afrose A, Islam N. Formulation and delivery strategies of ibuprofen: Challenges and opportunities. Drug Dev Ind Pharm 2018;44:173-83.

55. Kelchen MN, Brogden NK. Effect of dosing regimen and microneedle pretreatment on in vitro skin retention of topically applied betablockers. Biomed Microdevices 2018;20:100.

56. Mahajan NM, Zode GH, Mahapatra DK, Thakre S, Dumore N, Gangane PS. Formulation development and evaluation of transdermal patch of piroxicam for treating dysmenorrhoea. J Appl Pharm Sci 2018;8:35-41

57. McCrudden MT, Larrañeta E, Clark A, Jarrahian A, ReinWeston A, Creelman B, et al. Design, formulation, and evaluation of novel dissolving microarray patches containing rilpivirine for intravaginal delivery. Adv Healthc Mater 2019;8:1-12.

58. Chime SA, Onunkwo GC, Attama AA. Evaluation of the properties of encapsulated stavudine microparticulate lipid-based drug delivery system in immunocompromised wistar rats. Curr HIV Res 2020;18:237-47

59. Yamsani VV, Mudulaghar MK, Afreen S, Wajid S, Ravula SK, Babelghaith SD. Formulation design and in vitro ex vivo evaluation of transdermal patches of cinnarizine. Pak J Pharm Sci 2017;30:2075-83.

60. Samal D, Mishra N, Meher B, Kar IB, Kar R, Saipooja RH. Comparison of safety, efficacy, patient compliance and cost-effectiveness of transdermal, oral and intramuscular diclofenac for pain control following oral surgical procedures. J Maxillofac Oral Surg 2021;20:63-9.

61. McNicol ED, Ferguson MC, Schumann R. Single-dose intravenous ketorolac for acute postoperative pain in adults. Cochrane Database Syst Rev 2021;5:CD013263.

62. Kołodziejska J, Kołodziejczyk M. Diclofenac in the treatment of pain in patients with rheumatic diseases. Reumatologia 2018;56:174-83.

63. Mandal A, Bisht R, Rupenthal ID, Mitra AK. Polymeric micelles for ocular drug delivery: From structural frameworks to recent preclinical studies. J Control Release 2017;248:96-116.
64. Jafri I, Shoaib MH, Yousuf RI, Ali FR. Design and evaluation of matrix diffusion controlled transdermal patches of verapamil hydrochloride. Drug Dev Ind Pharm 2003;29:495-503.

65. Marapur SC, Wali DS, Hunasagi BS, Chetankumar M, Patil RG. Formulation and evaluation of transdermal drug delivery system of verapamil hydrochloride. J Drug Deliv Ther 2018;8:70-7.

66. Deshpande TM, Quadir A, Obara S, Hoag SW. Impact of formulation excipients on the thermal, mechanical, and electrokinetic properties of hydroxypropyl methylcellulose acetate succinate (HPMCAS). Int J Pharm 2018;542:132-41

67. Sravanthi K, Reddy DR, Sirisha A, Pavani A, Lakshmi BK, Sowjanya B. Preparation and in vitro evaluation of transdermal patch of aceclofenac. J Pharmtechnol Res 2020;10:175-81.

68. van Rensburg R, Reuter H. An overview of analgesics: NSAIDs, paracetamol, and topical analgesics. S Afr Family Pract 2019;61:S4-10.

69. Akram MR, Ahmad M, Abrar A, Sarfraz RM, Mahmood A. Formulation design and development of matrix diffusion controlled transdermal drug delivery of glimepiride. Drug Des Dev Ther 2018;12:349-64.

70. Mamatha J, Gadili S, Pallavi K. Formulation and evaluation of zidovudine transdermal patch using permeation enhancers. J Young Pharm 2020;12 Suppl 2:S45-50.

71. Charoensumran P, Ajiro H. Cationic moieties in polystyrene gels swollen with d-limonene improved transdermal delivery system. Polymers (Basel) 2018;10:1200.

72. Naiserová M, Kubová K, Vysloužil J, Bernatoniene J, Brokalakis I, Vetchý D. (Meth)acrylate copolymers of Eudragit ${ }^{\circledR}$ type in oral tablet technology. Ceska Slov Farm 2019;68:183-97.

73. Dutta L, Mukherjee B, Chakraborty T, Das MK, Mondal L, Bhattacharya $\mathrm{S}$, et al. Lipid-based nanocarrier efficiently delivers highly water soluble drug across the blood-brain barrier into brain. Drug Deliv 2018;25:504-16

74. Bajracharya R, Song JG, Back SY, Han SK. Recent advancements in non-invasive formulations for protein drug delivery. Comput Struct Biotechnol J 2019;17:1290-308.

75. Ammar HO, Tadros MI, Salama NM, Ghoneim AM. EthosomeDerived invasomes as a potential transdermal delivery system for vardenafil hydrochloride: Development, Optimization and application of physiologically based pharmacokinetic modeling in adults and geriatrics. Int J Nanomed 2020;15:5671-85.

76. Tawfik MA, Tadros MI, Mohamed MI, El-Helaly SN. Low-frequency versus high-frequency ultrasound-mediated transdermal delivery of agomelatine-loaded invasomes: Development, optimization and in-vivo pharmacokinetic assessment. Int J Nanomed 2020;15:8893-910.

77. Lundgren M, Steed LJ, Tamura R, Jonsdottir B, Gesualdo P, Crouch C, et al. Analgesic antipyretic use among young children in the TEDDY study: No association with islet autoimmunity. BMC Pediatr 2017;17:127.

78. Gyöngyösi A, Verner V, Bereczki I, Kiss-Szikszai A, Zilinyi R, Tósaki A, et al. Basic pharmacological characterization of EV-34, a New H2S-releasing ibuprofen derivative. Molecules 2021;26:599.

79. Jones P, Lamdin R, Dalziel SR. Oral non-steroidal anti-inflammatory drugs versus other oral analgesic agents for acute soft tissue injury. Cochrane Database Syst Rev 2020;8:CD007789.

80. Coderch L, Collini I, Carrer V, Barba C, Alonso C. Assessment of finite and infinite dose in vitro experiments in transdermal drug delivery. Pharmaceutics 2021;13:364

81. Uchida T, Kadhum WR, Kanai S, Todo H, Oshizaka T, Sugibayashi K. Prediction of skin permeation by chemical compounds using the artificial membrane, Strat-MTM. Eur J Pharm Sci 2015;67:113-8.

82. Tombs EL, Nikolaou V, Nurumbetov G, Haddleton DM. Transdermal delivery of ibuprofen utilizing a novel solvent-free pressure-sensitive adhesive (PSA): TEPI ${ }^{\circledR}$ technology. J Pharm Innov 2018;13:48-57. 